\title{
Long-Term Inhibition of Murine Experimental Autoimmune Encephalomyelitis Using CTLA-4-Fc Supports a Key Role for CD28 Costimulation
}

\author{
Anne H. Cross, * Thomas J. Girard, ${ }^{\ddagger}$ Karen S. Giacoletto, ${ }^{*}$ Robert J. Evans, ${ }^{\ddagger}$ Richard M. Keeling, * Robin F. Lin, * \\ John L. Trotter, * and Robert W. Karr ${ }^{*}$ \\ *Department of Neurology and Neurosurgery, Washington University School of Medicine, St. Louis, Missouri 63110; and ${ }^{\ddagger}$ Department \\ of Immunology, G. D. Searle \& Co., St. Louis, Missouri 63198
}

\begin{abstract}
$T$ cell activation involves not only recognition of antigen presented by the MHC, but also nonspecific interactions termed "costimulation." The costimulatory molecules B71 and B7-2 are ligands on antigen-presenting cells for the CD28 and CTLA-4 receptors on T cells. Previously, a fusion protein consisting of human CTLA-4 linked to human Fc was shown to bind B7-1 and B7-2 with high avidity and to prevent specific $T$ cell activation. Here we investigated the effects of a recombinant fusion protein consisting of the extracellular domain of human CTLA-4 bound to mouse IgG2a Fc (CTLA-4-Fc) upon experimental autoimmune encephalomyelitis, a $\mathbf{T}$ cell-mediated disease that serves as a model for multiple sclerosis. CTLA-4-Fc prevented experimental autoimmune encephalomyelitis in 26 of 28 CTLA-4Fc-treated mice (median maximum score 0 ), whereas 28 of 30 mice treated with control mouse IgG2a developed disease (median maximum score 2.75). Less inflammation and virtually no demyelination or axonal loss occurred in CTLA-4Fc-treated compared with control-treated mice. Activated splenocytes from CTLA-4-Fc-treated mice were able to transfer disease adoptively to naive recipients. These results indicate a key role for the B7/CD28 system in the development of actively induced murine experimental autoimmune encephalomyelitis, suggesting an area of investigation with therapeutic potential for multiple sclerosis. (J. Clin. Invest. 1995. 95:2783-2789.) Key words: allergic encephalomyelitis - demyelinating disease $-\mathrm{T}$ lymphocyte $\cdot$ autoimmune disease $\cdot T$ cell costimulation
\end{abstract}

\section{Introduction}

Antigen-specific $\mathrm{T}$ cell activation requires not only the TCRmediated signal after recognition by the TCR of processed antigen presented in the context of MHC molecule, but also a second, nonspecific signal, termed costimulation, that is the result of other receptor-ligand interactions (1). One costimulatory pathway involves the interaction of B7-1 and B7-2 mole-

Address correspondence to Dr. Anne H. Cross, Box 8111, Department of Neurology, Washington University School of Medicine, 660 South Euclid Avenue, St. Louis, MO 63110. Phone: 314-362-3293; FAX: 314362-2826. 1995.

Received for publication 8 July 1994 and in revised form 23 January

J. Clin. Invest.

(c) The American Society for Clinical Investigation, Inc.

0021-9738/95/06/2783/07 \$2.00

Volume 95, June 1995, 2783-2789 cules on antigen-presenting cells with the CD28 molecule on $T$ cells and results in paracrine levels of $I L-2$ secretion and proliferation (2-6). Importantly, inhibition of CD28 costimulation in conjunction with delivery of the TCR-mediated signal can result in $T$ cell anergy or hyporesponsiveness (7-9). CTLA-4 is a second receptor on T cells for B7-1 and B7-2 (10) and is homologous to CD28 (11). Although CTLA-4 binds B71 with 20-fold higher avidity than CD28 (10), a clear role for CTLA -4 in T cell activation has not been demonstrated (12). Because CTLA-4 binds to B7-1 and B7-2 with high avidity and this binding occurs across species (13), a fusion protein of human CTLA-4 and the Fc region of Ig has been useful in studies of the effects of inhibition of CD28 costimulation. CTLA-4-Fc has been shown to inhibit specific T cell activation both in vitro (10) and in vivo (14-17).

To investigate a role for CD28 costimulation in central nervous system (CNS) autoimmune demyelination, we used experimental autoimmune encephalomyelitis (EAE), ${ }^{1}$ a $\mathrm{T}$ cell-mediated inflammatory demyelinating disease that serves as a prime model for human multiple sclerosis (MS) $(18,19)$. EAE is known to be induced by $\mathrm{CD}^{+} \mathrm{T}$ cells $(20,21)$. The pathogenesis of MS, though not fully understood, also appears to involve activated $\mathrm{T}$ cells $(22-25)$. The current studies investigated in EAE the effects of systemic therapy with a recombinant fusion protein consisting of human CTLA-4 and murine IgG2a Fc upon the clinical course, CNS histologic changes, and generation of encephalitogenic, IL-2-producing T cells.

\section{Methods}

Mice. Pathogen-free female SJL/J mice aged 6-12 wk (the Jackson Laboratories, Bar Harbor, ME) were housed and maintained in microisolator cages in accordance with guidelines of the Washington University Committee for the Humane Care of Laboratory Animals and the National Institutes of Health regarding laboratory animal welfare. Sentinel mice were periodically checked for infection, and none was found.

Antigens and EAE induction. CNS myelin was purified from guinea pig spinal cords (Rockland, Gilbertsville, PA) as described (26), emulsified in a 1:1 mixture of sterile saline and complete Freund's adjuvant (Difco Laboratories Inc., Detroit, MI), and injected subcutaneously at two sites on the back (base of tail and dorsal neck) to induce EAE. Each mouse received $0.5 \mathrm{mg}$ of whole myelin in $0.1 \mathrm{ml}$ of emulsion and $200 \mathrm{ng}$ of pertussis toxin (List Laboratories, Campbell, CA) dissolved in $100 \mu \mathrm{l}$ of sterile PBS administered intravenously on days 0,2 , and 7 postimmunization (PI). Clinical disease was scored from 0 to 5 in a blind fashion at least $6 \mathrm{~d} / \mathrm{wk}$ according to accepted criteria (20). Re-

1. Abbreviations used in this paper: CNS, central nervous system; CTLA-4-Fc, CTLA-4 bound to murine IgG2a; EAE, experimental autoimmune (allergic) encephalomyelitis; LNC, lymph node cell; MBP, myelin basic protein; MS, multiple sclerosis; PI, postimmunization; PLP, proteolipid protein; SC, spleen cell. 
lapses were defined as worsening by at least 1 point lasting at least 2 d. Mice were weighed weekly during the acute EAE time period.

CTLA-4-Fc and control Ig. A soluble fusion protein consisting of the extracellular domain of human CTLA-4 and a mouse IgG2a Fc was prepared. The Fc region of mouse IgG2a was generated by reverse transcription followed by PCR amplification using poly (A) ${ }^{+}$RNA isolated from the L243 hybridoma cell line (ATCC HB 55; American Type Culture Collection, Rockville, MD) and the IgG2a-specific sense primer 5'-GATCGGATCCGAGCCCAGAGGGCCCACAATCAAGCC-3' and antisense primer $5^{\prime}$-GATCAAGCTTAGATCTTATCATTTACCCGGAGTCCGGGAGAA-3' (27). The purified PCR product was digested with BamHI and BglII and cloned into the BamHI site of pMON3360B (28), yielding plasmid pMON24210. The signal peptide and extracellular domain of CTLA-4 was generated by PCR amplification using a thymus cDNA library (HL1074a; Clontech, Palo Alto, CA) as template and the CTLA-4-specific sense primer 5'-CCATGGATCCATGGCTTGCCTTGGATTTCAG-3' and the antisense primer 5'GATCGGATCCGAAGTCAGAATCTGGGCACGGTTC-3' (11). The purified BamHI digested product was cloned into the BamHI site of pMON24210, yielding transfection vector pMON24218. Transfection and isolation of a stable cell line expressing 2-5 $\mu \mathrm{g} / \mathrm{ml} \mathrm{CTLA-4-Fc}$ were performed as previously described (28), using Western blot analysis developed with goat anti-mouse $\mathrm{Fc}$ to identify the recombinant protein. Recombinant CTLA-4-Fc was purified using protein A affinity chromatography. A purified mouse myeloma IgG2a antibody (UPC-10; Sigma Chemical Co., St. Louis, MO) was used as a control treatment. Mice received $75 \mu \mathrm{g}$ per dose CTLA-4-Fc or control antibody in 200 $\mu \mathrm{l}$ of sterile PBS on the day before and the day of immunization and then 3 times per week for a total of 10 doses $(0.75 \mathrm{mg})$. The investigator administering the treatments was blinded as to the contents of the syringes.

CNS histology. Mice were anesthetized with methoxyfluorane and perfused with buffered $2.5 \%$ glutaraldehyde. One mouse (A554; see Fig. 1 and Table I) was perfused on day 16 PI at grade 4.5 (moribund), along with a matched counterpart (A548). The additional eight mice were also perfused in pairs during acute EAE within the period of active treatment. CNS tissues were removed, postfixed in $1 \%$ osmium tetroxide (Electron Microscopy Sciences, Fort Washington, PA), dehydrated through graded alcohols, and embedded in EMBED 812 (Electron Microscopy Sciences) as described (29). 8-16 1- $\mu \mathrm{M}$ thick tissue sections taken from each level of the CNS (optic nerves, cerebrum, cerebellum, brainstem, and cervical, thoracic lumbar, and sacral spinal cord regions) were placed on glass slides, stained with toluidine blue, and assessed blindly from 0 to 5 for inflammation, demyelination, axonal necrosis (30). These data were subjected to statistical analysis.

Proliferation assays. Guinea pig myelin basic protein (MBP) was purified from guinea pig spinal cords (Rockland, Gilbertsville, PA) as described (31). Proteolipid protein (PLP) was purified from normal brain obtained at autopsy as described (32). The major encephalitogenic SJL epitope of PLP, amino acids 139-151 (HCLGKWLGHPDKF; reference 33), and the major SJL encephalitogenic epitope of MBP, amino acids 87-99 (VHFFKNIVTPRTP), were synthesized using an automated peptide synthesizer (model 431A; Applied Biosystems, Inc., Foster City, CA) using FastMOC chemistry by the Protein and Nucleic Acid Chemistry Laboratory at Washington University School of Medicine (St. Louis, MO). Proliferation assays were performed on draining lymph node cells (LNCs) and splenocytes from four mice in each treatment group, at 15 or $16 \mathrm{~d}$ PI. Cells were cultured at $8 \times 10^{5}$ per well in quadruplicate in 96-well plates with media alone; whole MBP (at 25, 50, and $100 \mu \mathrm{g} / \mathrm{ml}$ ); whole PLP (at 25,50 , and $100 \mu \mathrm{g} / \mathrm{ml}$ ); MBP 87-99 (at 10, 20, and $50 \mu \mathrm{g} / \mathrm{ml}$ ); PLP 139-151 (at 10, 20, and $50 \mu \mathrm{g} / \mathrm{ml}$ ); or $2 \mu \mathrm{g} / \mathrm{ml}$ Con A (Sigma Chemical Co.). During the final $18 \mathrm{~h}, 0.5 \mu \mathrm{Ci}$ per well [methyl- ${ }^{3} \mathrm{H}$ ] thymidine $(25 \mathrm{Ci} / \mathrm{mmol}$; Amersham Corp., Arlington Heights, $\mathrm{IL}$ ) was added to each well. The plates were then harvested (Tomtec, Orange, CT) and counted by liquid scintillation using a Betaplate 1205 (Wallac, Gaithersburg, MD).

IL-2 bioassay. The IL-2/4-dependent CTLL-2 cell line was used for the bioassay of IL-2 in the supernatants of spleen cells (SCs) from

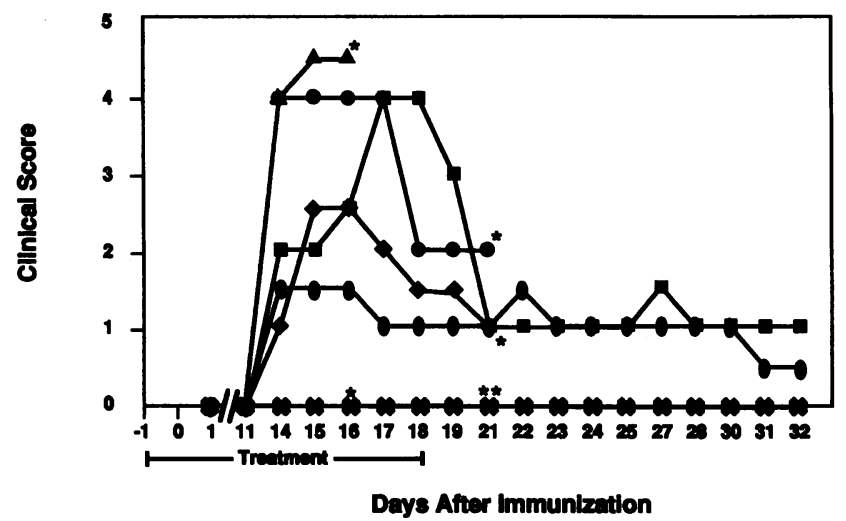

Figure 1. The clinical course in a representative experiment. All five control-treated mice developed EAE ( $\bullet$, A550; •, A551; — , A552; $\bullet$, A553; $\triangle$, A554). All five mice treated with CTLA-4-Fc remained clinical grade 0 during the time of observation $(\mathrm{X})$. Treatments began at day 1 and ceased on day 18. Mice sacrificed for histology are denoted by an asterisk. The grade 4.5 control-treated mouse $(\Delta)$ perfused on day 16 was sacrificed owing to its moribund state. By study design, a CTLA-4-Fc-treated counterpart was perfused at the same time.

mice from the two treatment groups according to published methods (34). Briefly, the supernatants of 48-h cultures activated with $20 \mu \mathrm{g} /$ ml PLP139-151 were added in serial dilutions in triplicate to CTLL-2 cells seeded in 96-well, flat-bottomed plates, and proliferation of the CTLL-2 cells was measured by incorporation of tritiated thymidine as previously described. In preliminary experiments, the ability of SCs to generate IL-2 was shown to be dependent on peptide 139-151 dose, with $20 \mu \mathrm{g} / \mathrm{ml}$ as an optimal dose. To assess the contribution of IL-2 versus IL-4 to CTLL-2 proliferation, $50 \mu \mathrm{g} / \mathrm{ml}$ rat anti-IL-2 mAb (31 $\mu \mathrm{g} / \mathrm{ml}$ neutralized $1 \mathrm{U} / \mathrm{ml}$ IL-2; Genzyme Corp., Boston, MA) was added to wells containing $12.5-100 \%$ supernatant in parallel to untreated wells.

Serial transfer of EAE. SCs from six CTLA-4-Fc-treated mice obtained at $16 \mathrm{~d}$ PI were cultured at $8 \times 10^{6}$ cells per 2-ml well in RPMI 1640 plus $10 \%$ FBS with either $50 \mu \mathrm{g} / \mathrm{ml}$ MBP (one recipient), $2 \mu \mathrm{g} / \mathrm{ml}$ Con A (one recipient), or $20 \mu \mathrm{g} / \mathrm{ml}$ PLP peptide 139-151 (four recipients) for $48 \mathrm{~h}$ and washed twice before intravenous injection of $10^{8}$ cells into each naive syngeneic recipient. $10^{8} \mathrm{SCs}$ from six control-treated mice ( $16 \mathrm{~d}$ PI) cultured with $50 \mu \mathrm{g} / \mathrm{ml} \mathrm{MBP}$ (one recipient), $2 \mu \mathrm{g} / \mathrm{ml}$ Con A (one recipient), or $20 \mu \mathrm{g} / \mathrm{ml}$ PLP peptide 139151 (two recipients) were injected intravenously into naive syngeneic recipients.

Statistical analyses. Comparisons of the maximum clinical scores were done using the nonparametric Van der Waerden two-sample test of the rank scores, which does not make distributional assumptions about the variability within groups. For the analysis of the histological data, a Split-Plot factorial design ANOVA was used to test for overall group differences in inflammation, demyelination, and axonal necrosis.

\section{Results}

Clinical. CTLA-4-Fc treatment completely prevented development of clinical EAE in 26 of 28 CTLA-4-Fc-treated mice (Fig. 1 depicts a representative experiment). 28 of the 30 control-treated mice developed EAE, with mean onset at 13.8 \pm 1.7 $\mathrm{d}$ PI and with a median maximum clinical score of 2.75 (mean maximum clinical score $2.8 \pm 1.4$ ). Comparison of the maximum clinical scores for each animal from the two treatment groups revealed a significant clinical benefit with CTLA-4-Fc $(P<0.0001)$. During the acute EAE period, the CTLA-4-Fc- 

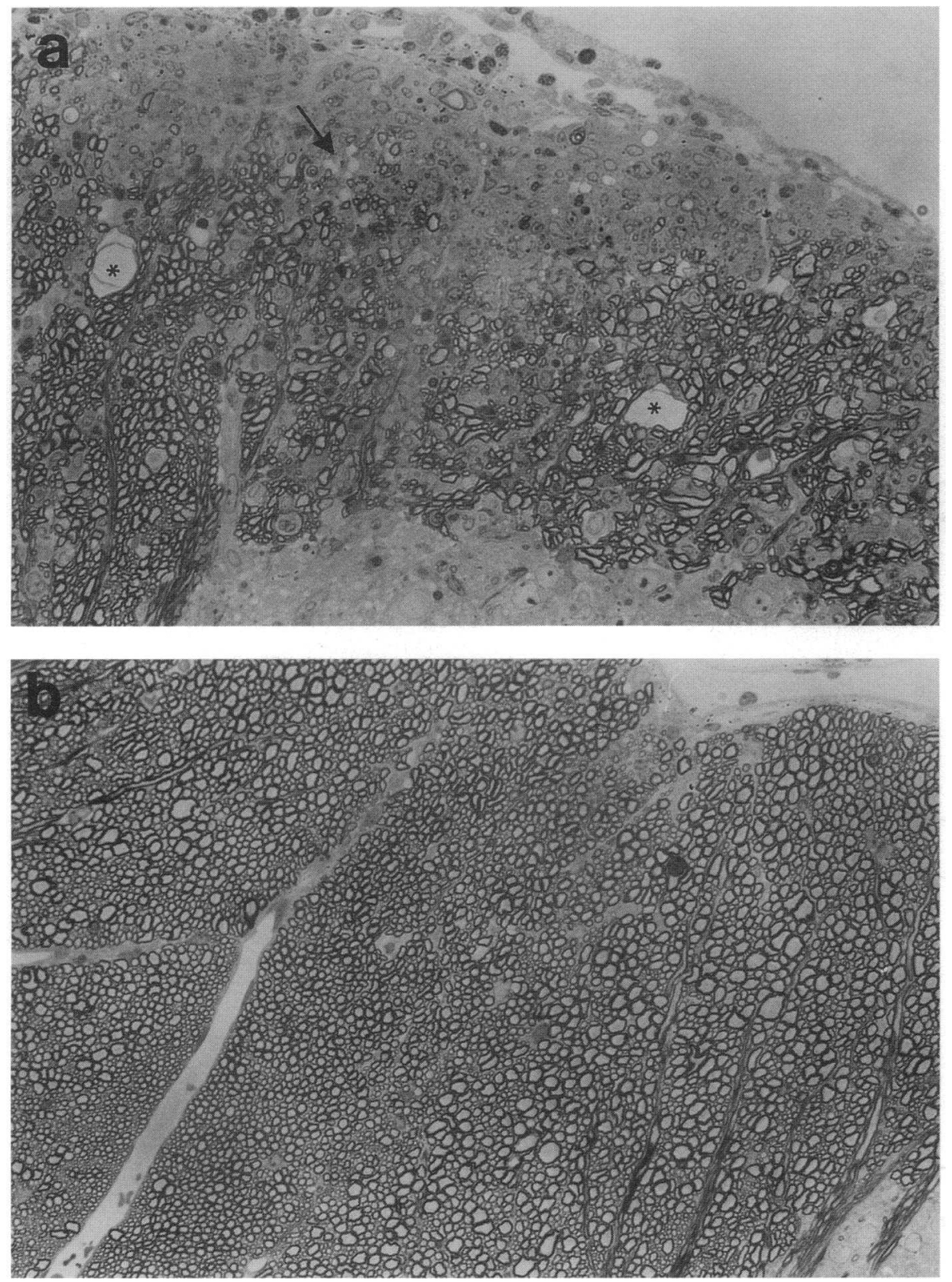

Figure 2. Representative CNS sections from CTLA-4-Fc-and control-treated mice. (a) SJL mouse, clinical grade 4, $16 \mathrm{~d}$ PI with CNS myelin, treated with control IgG2a. A $1-\mu \mathrm{m}$ plastic-embedded section from the anterior columns of the lower lumbar spinal cord shows a demyelinated lesion within the CNS parenchyma beneath the meningeal surface. Note the numerous inflammatory cells, extensive gliosis, clusters of healthy appearing demyelinated axons (arrow), and occasional necrotic axons (asterisks). Inflammatory cells are located in the CNS parenchyma as well as in the perivascular space and meninges. Anterior horn gray matter is at the lower edge (toluidine blue stain, $\times 400$ ). (b) SJL mouse, clinical grade 0,16 d PI, treated with CTLA-4-Fc. A 1- $\mu \mathrm{m}$ section from the lower lumbar spinal cord shows healthy appearing myelinated axons. Perhaps two lymphocytes can be discerned attached to the meningeal vessel above. The anterior horn is at the lower right (toluidine blue stain, $\times 400$ ). treated group maintained normal body weights, whereas the control-treated group lost a mean of $11 \%$ (range $=0-25 \%$ ) of body weight. Seven mice (four CTLA-4-Fc treated, three control treated) were not sacrificed for histology or serial transfer but were maintained and followed clinically for 14-17 wk after cessation of treatment on day 18 PI. All three control-treated mice had clinical relapses superimposed upon chronic disease, after cessation of treatment. None of the CTLA-4-Fc-treated mice ever developed clinical EAE. The overall health of the CTLA-4-Fc recipients remained good throughout the study.

CNS histopathology. To determine whether CNS pathology corresponded with clinical findings, 10 mice (5 CTLA-4-Fc treated, 5 control treated) were perfused in pairs for histologic analysis. Three pairs were sacrificed at day 16 PI (one pair from experiment 1, two pair from experiment 2) and two pairs at day 21 PI (both pairs from experiment 1). Blinded scoring of all levels of the CNS for inflammation, demyelination, and axonal necrosis revealed significantly less inflammation ( $P$ $=0.004)$, demyelination $(P=0.004)$, and necrosis $(P$ $=0.022)$ in the CTLA-4-Fc-treated group overall. Demyelination and axonal necrosis were almost absent in the CNS of CTLA-4-Fc-treated mice when compared with the CNS of control-treated mice (Fig. 2, $a$ and $b$ ). Table I shows histologic scores for the spinal cord, the area of greatest pathologic involvement in this model.

Proliferation studies. Lymphoid cells derived from controltreated and CTLA-4-Fc-treated mice proliferated to peptide 139-151 of PLP in each of 14 experiments over a time period ranging from 7 to $35 \mathrm{~d}$ PI (Fig. 3). However, proliferation to PLP peptide was less in cells from the CTLA-4-Fc-treated group in 11 of 14 experiments. The decreased proliferation was most pronounced at the earlier time points and equalized at later times PI. In comparison, proliferative responses to Con A were similar in both groups of cells (data not shown). No significant 
Table I. Histologic Analyses of Spinal Cord Tissues from CTLA-4-Fc-and Control IgG2a-treated Mice

\begin{tabular}{|c|c|c|c|c|c|c|c|c|}
\hline \multirow[b]{2}{*}{ Spinal cord region } & \multicolumn{4}{|c|}{ CTLA-4-Fc-treated mice } & \multicolumn{4}{|c|}{ Control IgG2a-treated mice } \\
\hline & Mouse & Inflammation & Demyelination & Necrosis & Mouse & Inflammation & Demyelination & Necrosis \\
\hline Cervical and thoracic & A548 & 0.0 & 0.0 & 0.0 & A554 & 2.7 & 1.5 & 0.7 \\
\hline Lumbar and sacral & A548 & 0.0 & 0.0 & 0.0 & A554 & 3.0 & 2.1 & 0.8 \\
\hline Cervical and thoracic & A545 & 1.0 & 0.5 & 0.0 & A550 & 2.1 & 1.0 & 0.8 \\
\hline Lumbar and sacral & A545 & 1.1 & 0.1 & 0.0 & A550 & 2.2 & 1.3 & 1.5 \\
\hline Cervical and thoracic & A547 & 1.0 & 0.0 & 0.0 & A551 & 1.6 & 2.0 & 2.4 \\
\hline Lumbar and sacral & A547 & 1.6 & 0.3 & 0.0 & A551 & 2.2 & 3.1 & 2.8 \\
\hline Cervical and thoracic & A576 & 0.0 & 0.0 & 0.0 & A583 & 3.5 & 2.0 & 0.5 \\
\hline Lumbar and sacral & A576 & 0.1 & 0.0 & 0.0 & A583 & 2.6 & 3.1 & 1.8 \\
\hline Cervical and thoracic & A578 & 0.2 & 0.0 & 0.0 & A586 & 1.1 & 0.3 & 0.3 \\
\hline Lumbar and sacral & A578 & 0.3 & 0.0 & 0.0 & A586 & 2.3 & 0.5 & 0.0 \\
\hline
\end{tabular}

Inflammation, demyelination, and axonal necrosis were scored as described in Methods. Numbers represent the mean score of two to four slides.

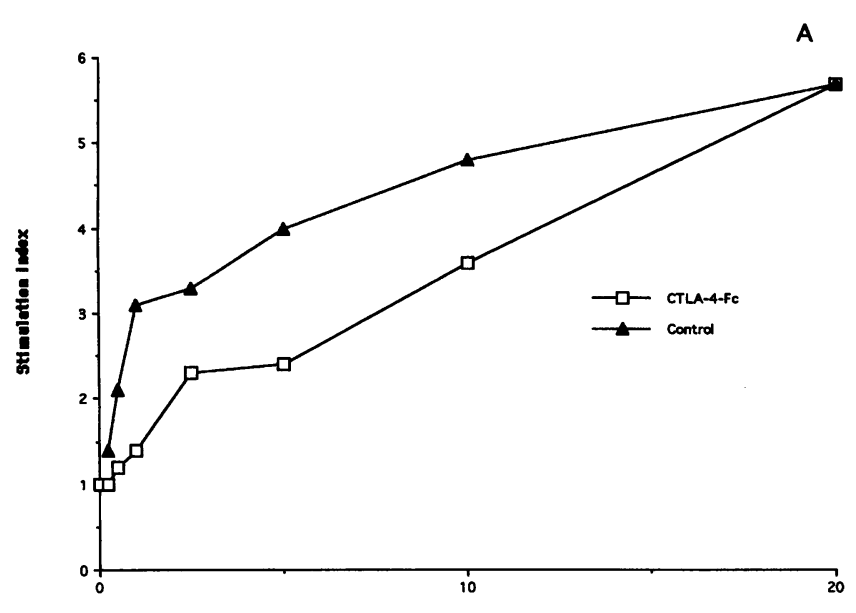

PLP 139-151 (micrograms/ml)

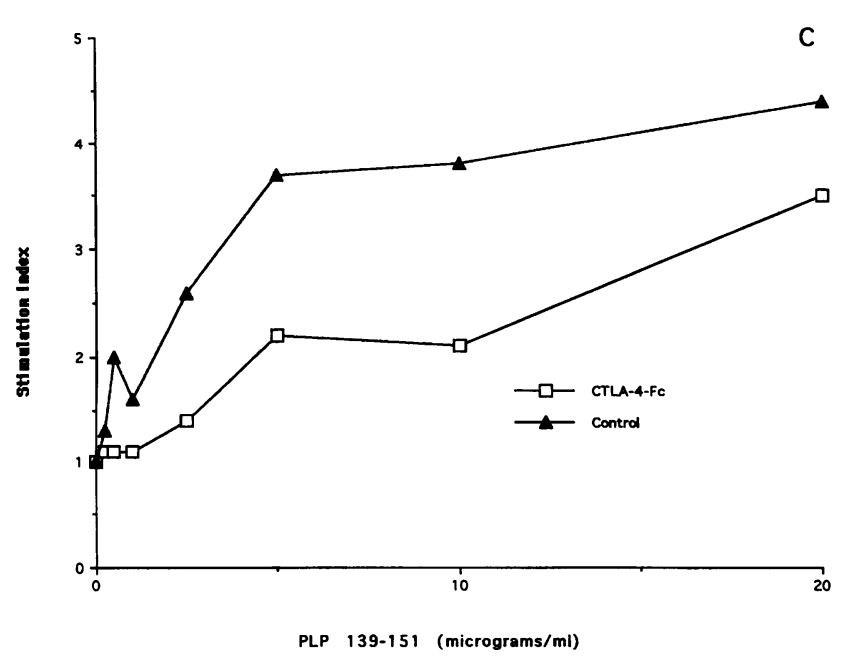

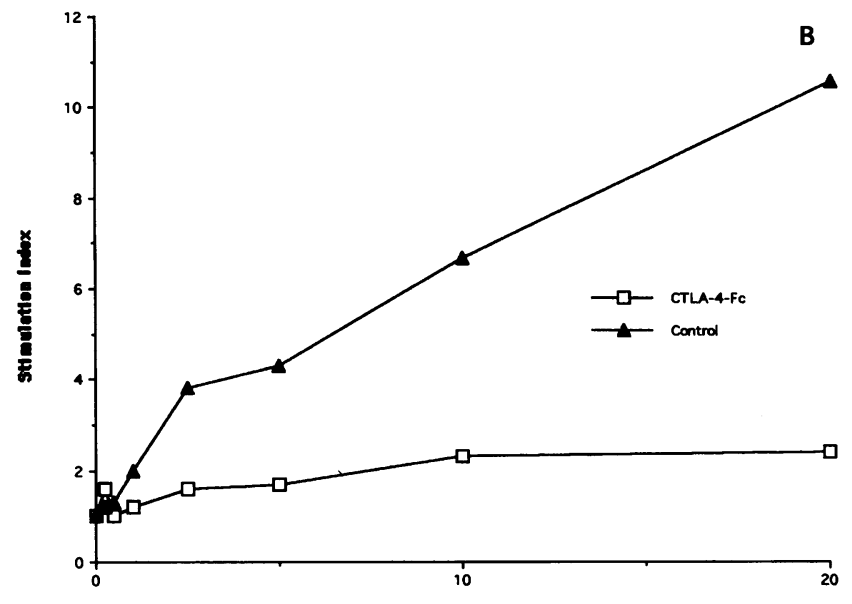

PLP 139-151 (micrograms/ml)

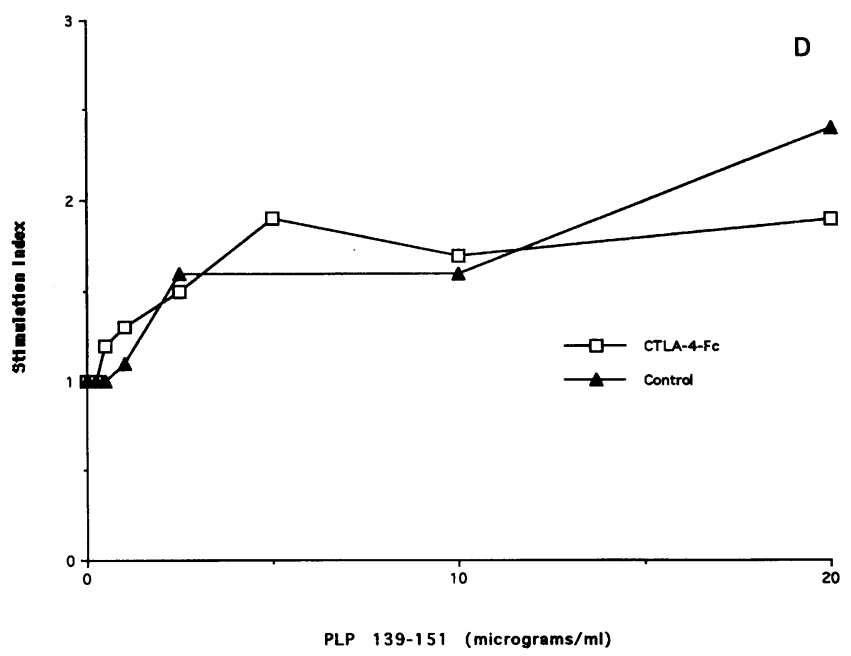

Figure 3. Proliferation by draining LNCs to PLP peptide 139-151. Comparisons of the specific proliferation to varying doses of PLP peptide 139151 by LNCs from CTLA-4-Fc-treated $(\square)$ and control IgG2a-treated ( $\triangle$ ) mice at $7 \mathrm{~d}$ PI $(A) 12 \mathrm{~d}$ PI $(B), 15 \mathrm{~d}$ PI $(C)$, and $35 \mathrm{~d}$ PI $(D)$. Stimulation index $=$ mean proliferation with antigen/mean proliferation in the absence of antigen. 
proliferation to whole PLP, whole MBP, or the encephalitogenic MBP peptide 87-99 was observed in cells from either group.

$I L-2$ bioassay. Bioassays were performed on SCs owing to insufficient numbers of draining LNCs to perform both proliferation and IL-2 assays. Splenocytes from both treatment groups (7-20 d PI) elaborated IL-2 upon activation in vitro with 20 $\mu \mathrm{g} / \mathrm{ml}$ PLP $139-151$ in six separate experiments. CTLL-2 proliferation was abolished by the addition of antibody to IL-2, confirming that IL-2 (and not IL-4) was responsible for CTLL2 cell proliferation. Decreased IL- 2 was noted in the supernatants of SCs derived from the CTLA-4-Fc-treated mice when compared with the control-treated mice (Fig. 4).

Serial transfer experiments. To determine whether $\mathrm{T}$ cells capable of inducing EAE were present and functional in CTLA4-Fc-treated mice, SCs from CTLA-4-Fc-treated mice were activated by culturing with antigen or mitogen for $48 \mathrm{~h}$ before transfer into normal SJL females. PLP peptide-activated SCs from CTLA-4-Fc-treated mice activated with the encephalitogenic 139-151 amino acid peptide of PLP transferred typical clinical EAE into four of four naive recipients, with all animals unequivocally ill by day 9 after cell transfer. The maximum clinical scores of these animals were 2.0, 2.5, 2.5, and 3.5. SCs from control-treated mice also transferred EAE into two of two recipients after activation in vitro with PLP 139-151, with maximum clinical scores of 2.0 and 4.0 and onset by day 9 after transfer. SCs from neither CTLA-4-Fc-nor control-treated mice transferred EAE after a 2-d culture with MBP or Con A, even though large numbers of cells $\left(10^{8}\right)$ were transferred. Histologic analysis was performed on the CNS of two of the six recipients of PLP peptide-activated SCs from CTLA-4-Fctreated mice, revealing marked inflammation and demyelination and mild to moderate axonal necrosis in both cases, which are typical histologic features of EAE (29).

\section{Discussion}

EAE serves as a prime model for the study of $\mathrm{T}$ cell-mediated inflammatory CNS demyelination, as observed in MS. A variety of therapies directed at disease-inducing T cells (e.g., 35-39) have been effective in inhibiting EAE induced in highly inbred rodent strains with a known antigen, though none have yet been successfully applied in the treatment of ("outbred") MS patients. As with other T cell-mediated autoimmune diseases, the ideal therapy for MS should inhibit putative autoimmune $\mathrm{T}$ cells without interfering with the normal immune functions of other T cells. Practically, MS therapies must be effective despite being first administered after initiation of the immune event and should not depend upon precise knowledge of the autoantigen. In the present work, a controlled, blinded study of the effect of the fusion protein CTLA-4-Fc upon murine EAE induced with CNS myelin was performed. We found a profound inhibition of the clinical and histologic manifestations of EAE, which continued after cessation of treatment with CTLA-4-Fc. These findings implied that costimulation delivered through CD28 was necessary for the function of EAE-inducing cells in this model for MS, since CTLA-4-Fc acts by blocking the CD28 ligands, B7-1 and B7-2. Myelin antigen-specific $T$ cell proliferation was decreased but present in CTLA-4-Fc-treated mice. Blockade of costimulation, by preventing the activation of $\mathrm{T}$ cells, would be expected to prevent the production of large quantities of IL-2 and result in the decreased production of other lymphokines
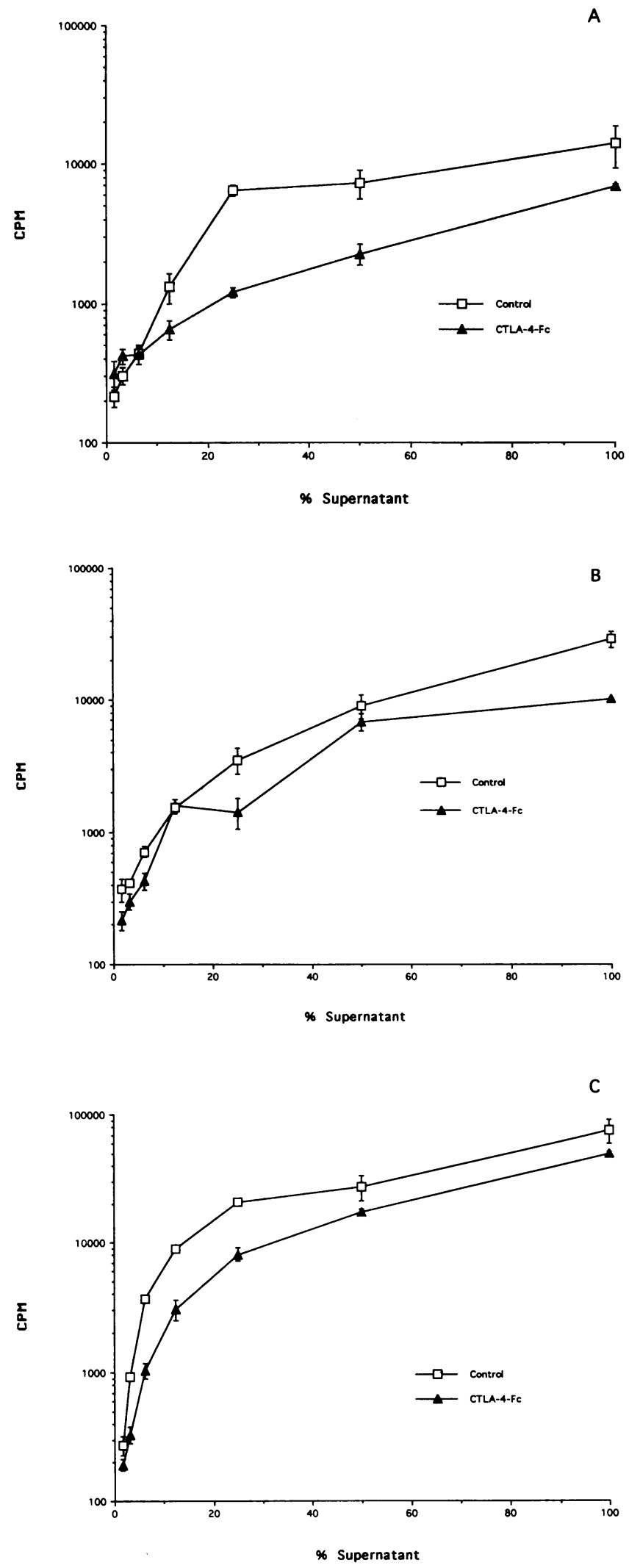

Figure 4. Bioassay of IL-2 in supernatants from CTLA-4-Fc-and control-treated mice. Comparisons of $\left[{ }^{3} \mathrm{H}\right]$ thymidine incorporation by CTLL-2 cells cultured with varying dilutions of supernatants derived from CTLA-4-Fc-treated $(\triangle)$ and control-treated $(\square)$ mice at $7 \mathrm{~d}$ PI $(A), 10 \mathrm{~d}$ PI $(B)$, and $15 \mathrm{~d}$ PI $(C)$. Proliferation was abrogated by the concomitant addition of $50 \mu \mathrm{g} / \mathrm{ml}$ anti-IL-2 in $A$ and $B$. 
such as IFN- $\gamma$, lymphotoxin, and TNF $\alpha$ (40), which have been implicated in the pathogenesis of EAE and MS (41-46).

Previously, a recombinant fusion protein of human CTLA4 and human Fc was found to block the B7-1/B7-2:CD28 signaling pathway. This CTLA-4-Ig has been shown to inhibit T cell proliferation and IL-2 production in primary in vitro responses and to induce $\mathrm{T}$ cell hyporesponsiveness or anergy to subsequent antigen challenge $(6,8,9)$. CTLA-4-Fc was shown to induce a state of long-term donor-specific tolerance in a xenogeneic pancreatic islet cell transplant model (14), compatible with $\mathrm{T}$ cell anergy. In other studies involving cardiac allograft transplantation using the same fusion protein, long-lasting tolerance was not achieved, although graft survival was modestly prolonged (16). In a related study, it was found that CTLA-4-Fc, when administered with donor-specific transfusion, was effective even after introduction of specific antigen, suggesting that it was acting upon events involved in the amplification rather than induction of the specific $T$ cell immune response (17). In further support of this notion, a recent study showed effective treatment of established murine lupus-like disease using CTLA-4-Ig (47). Thus, in previous studies, CTLA4-Fc treatment in vivo uniformly produced immunosuppression, but the induction of $\mathrm{T}$ cell anergy was variable. The present studies with CTLA-4-Fc resulted in highly effective long-term suppression of EAE concomitant with the development of lymphocytes in these successfully treated animals that could recognize the encephalitogenic epitope of the myelin antigen PLP and could transfer disease after in vitro culture (48). Therefore, CTLA-4-Fc treatment either did not induce anergy or induced $\mathrm{T}$ cell anergy in vivo that was overcome during in vitro culture before cell transfer. Furthermore, analyses of $\mathrm{IL}-2$ production by PLP peptide-activated SCs revealed supernatants of SCs from each treatment group to support growth of the IL-2-dependent cell line, CTLL-2, although there was less IL-2 in the supernatants from CTLA-4-Fc-treated mice. Taken together, these data suggest that CTLA-4-Fc very effectively blocked activation of EAE-inducing $\mathrm{T}$ cells in vivo, but did not prevent generation of cells (possibly memory $T$ cells) that could be activated in vitro to proliferate and to become encephalitogenic and transfer EAE. The immunoregulatory network that presumably prevents the in vivo activation of these cells remains to be determined.

Actively induced EAE presents the opportunity to study the effect of CTLA-4-Fc treatment upon naive $\mathrm{T}$ cells. Of note, recent studies indicate differing requirements for costimulation among naive versus memory $\mathrm{T}$ cells. Naive $\mathrm{T}$ cells appear to have more stringent requirements for costimulation $(49,50)$ than memory $\mathrm{T}$ cells. Memory cells may be activated in certain situations without costimulatory signaling, although activation is enhanced by costimulation (49). Treatment with an agent such as CTLA-4-Fc may not be effective if instituted after induction of an ongoing process with one antigen. However, recent data from several laboratories suggest special therapeutic possibilities for CD28 costimulation blockade in relapsing EAE and perhaps MS. We and others have demonstrated using the EAE model that during a CNS autoimmune process, acquisition of immunoreactivity to new CNS antigens (51-54) can occur. Thus, the possibility exists that intervention to block CD28 costimulation, even after the initiation of a CNS autoimmune process and the generation of memory $\mathrm{T}$ cells to one antigen, might prevent progression by blocking antigenic determinant spreading. The present data, indicating a crucial role for CD28 costimulation in actively induced EAE, suggest an area of investigation with potential for inhibition of the putative $T$ cellmediated autoimmune response in MS, even despite our current lack of knowledge of the identity of the MS autoantigen(s).

\section{Acknowledgments}

The authors wish to thank Dr. George Vogler (Washington University School of Medicine Division of Biostatistics) for help with statistical analyses and Cheryl Damico, Manuel San, Joe Goellner, Joshua Yoburn, and Lyn Kuo for excellent technical assistance. Dr. Michael K. Racke provided helpful discussion. Dr. Cross is a Harry Weaver Neuroscience Scholar of the National Multiple Sclerosis Society.

This work was supported by a grant from the National Multiple Sclerosis Society (JF 2059-A2) to A. H. Cross.

\section{References}

1. Mueller, D. L., M. K. Jenkins, and R. H. Schwartz. 1989. Clonal expansion versus functional clonal inactivation: a costimulatory signalling pathway determines the outcome of $\mathrm{T}$ cell antigen receptor occupancy. Annu. Rev. Immunol. 7:445-480.

2. Linsley, P. S., W. Brady, L. Grosmaire, A. Aruffo, N. K. Damle, and J. A. Ledbetter. 1991. Binding of the B cell activation antigen B7 to CD28 costimulates T cell proliferation and interleukin 2 mRNA accumulation. J. Exp. Med. 173:721 730.

3. Gimmi, C. D., G. J. Freeman, J. G. Gribben, K. Sugita, A. S. Freedman, C. Morimoto, and L. M. Nadler. 1991. B-cell surface antigen B7 provides a costimulatory signal that induces $\mathrm{T}$ cells to proliferate and secrete interleukin 2 . Proc. Natl. Acad. Sci. USA. 88:6575-6579.

4. Jenkins, M. K., P. S. Taylor, S. D. Norton, and K. B. Urdahl. 1991. CD28 delivers a costimulatory signal involved in antigen-specific IL-2 production by human T cells. J. Immunol. 147:2461-2466.

5. Azumi, M., D. Ito, H. Yagita, K. Okumura, J. H. Phillips, L. L. Lanier, and C. Somoza. 1993. B70 antigen is a second ligand for CTLA-4 and CD28. Nature (Lond.). 366:76-79.

6. Freeman, C. J., J. G. Gribben, V. A. Boussiotis, J. W. Ng, V. A. Restivo, Jr., L. A. Lombard, G. S. Gray, and L. M. Nadler. 1993. Cloning of B7-2: a CTLA-4 counter-receptor that costimulates human T cell proliferation. Science (Wash. DC). 262:909-911.

7. Harding, F. A., J. G. McArthur, J. A. Gross, D. H. Raulet, and J. P. Allison. 1992. CD28-mediated signaling co-stimulates murine $T$ cells and prevents induction of anergy in T-cell clones. Nature (Lond.). 356:607-609.

8. Tan, P., C. Anasetti, J. A. Hansen, J. Melrose, M. Brunvand, J. Bradshaw, J. A. Ledbetter, and P. S. Linsley. 1993. Induction of alloantigen-specific hyporesponsiveness in human $\mathrm{T}$ lymphocytes by blocking interaction of CD28 with its natural ligand B7/BB1. J. Exp. Med. 177:165-173.

9. Boussiotis, V. A., G. J. Freeman, G. Gray, J. G. Gribben, and L. M. Nadler. 1993. B7 but not intracellular adhesion molecule-1 costimulation prevents the induction of human alloantigen-specific tolerance. J. Exp. Med. 178:1753-1763.

10. Linsley, P. S., W. Brady, M. Urnes, L. S. Grosmaire, N. K. Damle, and J. A. Ledbetter. 1991. CTLA-4 is a second receptor for the B cell activation antigen B7. J. Exp. Med. 174:561-569.

11. Harper, K., C. Balzano, E. Rouveir, M.-G. Mattei, M.-F. Luciani, and P. Golstein. 1991. CTLA-4 and CD28 activated lymphocyte molecules are closely related in both mouse and human as to sequence, message expression, gene structure, and chromosomal location. J. Immunol. 147:1037-1044.

12. Linsley, P. S., J. L. Greene, P. Tan, J. Bradshaw, J. A. Ledbetter, C. Anasetti, and N. K. Damle. 1992. Coexpression and functional cooperation of CTLA-4 and CD28 on activated T lymphocytes. J. Exp. Med. 176:1595-1604.

13. Freeman, G. J., F. Borriello, R. J. Hodes, H. Reiser, J. G. Gribben, J. W. Ng, J. Kim, J. M. Goldberg, K. Hathcock, G. Laszlo, L. A. Lombard, S. Wang, G. S. Gray, L. M. Nadler, and A. H. Sharpe. 1993. Murine B7-2, an alternative CTLA4 counter-receptor that costimulates $\mathrm{T}$ cell proliferation and interleukin 2 production. J. Exp. Med. 178:2185-2192.

14. Lenschow, D. J., Y. Zeng, J. R. Thistlethwaite, A. Montag, W. Brady, M. G. Gibson, P. S. Linsley, and J. A. Bluestone. 1992. Long-term survival of xenogeneic pancreatic islet grafts induced by CTLA4Ig. Science (Wash. DC). 257:789-792.

15. Linsley, P. S., P. M. Wallace, J. Johnson, M. G. Gibson, J. L. Greene, J. A. Ledbetter, C. Singh, and M. A. Tepper. 1992. Immunosuppression in vivo by a soluble form of the CTLA-4 T cell activation molecule. Science (Wash. DC). 257:792-795.

16. Turka, L. A., P. S. Linsley, H. Lin, W. Brady, J. M. Leiken, R.-Q. Wei, M. L. Gibson, X.-G. Zheng, S. Myrdal, D. Gordon, T. Bailey, S. F. Bolling, and 
C. B. Thompson. 1992. T-cell activation by the CD28 ligand B7 is required for cardiac allograft rejection in vivo. Proc. Natl. Acad. Sci. USA. 89:11102-11105.

17. Lin, H., S. F. Bolling, P. S. Linsley, R.-Q. Wei, D. Gordon, C. B. Thompson, and L. A. Turka. 1993. Long-term acceptance of major histocompatibility complex mismatched cardiac allografts induced by CTLA4Ig plus donor-specific transfusion. J. Exp. Med. 178:1801-1806.

18. Alvord, E. D., M. W. Kies, and A. J. Suckling. 1984. Experimental allergic encephalomyelitis: a useful model for multiple sclerosis. Prog. Clin. Biol. Res. 146:1-554.

19. Raine, C. S. 1984. Biology of disease: the analysis of autoimmune demyelination: its impact on multiple sclerosis. Lab. Invest. 50:608-635.

20. Pettinelli, C. B., and D. E. McFarlin. 1981. Adoptive transfer of experimental allergic encephalomyelitis in SJL/J mice after in vitro activation of lymph node cells by myelin basic protein: requirement for Lyt ${ }^{+} 2^{+} \mathrm{T}$ lymphocytes. $J$. Immunol. 127:1420-1423.

21. Zamvil, S., P. Nelson, J. Trotter, D. Mitchell, R. Knobler, R. Fritz, and L. Steinman. 1985. T cell clones specific for myelin basic protein induce chronic relapsing paralysis and demyelination. Nature (Lond.). 317:355-358.

22. Traugott, U., E. Reinherz, and C. S. Raine. 1983. Multiple sclerosis distribution of $\mathrm{T}$ cell subsets within active chronic lesions. Science (Wash. DC). 219:308-310

23. Hauser, S. L., A. K. Bhan, F. Gilles, M. Kemp, C. Kerr, and H. L. Weiner. 1986. Immunohistochemical analysis of the cellular infiltrate in multiple sclerosis lesions. Ann. Neurol. 19:578-587.

24. Hofman, F. M., R. I. von Hanwehr, C. A. Dinarello, S. B. Mizel, D. Hinton, and J. E. Merrill. 1986. Immunoregulatory molecules and IL-2 receptors identified in multiple sclerosis brain. J. Immunol. 136:3239-3245.

25. Hafler, D. A., and H. L. Weiner. 1989. MS: a CNS and systemic autoimmune disease. Immunol. Today. 10:104-107.

26. Norton, W. T., and S. E. Poduslo. 1973. Myelination in rat brain: method of myelin isolation. $J$. Neurochem. 21:749-758.

27. Schreier, P. H., A. L. M. Bothwell, B. Mueller-Hill, and D. Baltimore. 1981. Multiple differences between the nucleic acid sequences of the $\operatorname{IgG}_{2} \mathrm{a}^{\mathrm{a}}$ and IgG2a ${ }^{b}$ alleles of the mouse. Proc. Natl. Acad. Sci. USA. 78:4495-4499.

28. Hippenmeyer, P., and M. Highkin. 1993. High level, stable production of recombinant proteins in mammalian cell culture using the herpesvirus VP16 transactivator. Bio/Technology. 11:1037-1041.

29. Raine, C. S., F. Mokhtarian, and D. E. McFarlin. 1984. Adoptively transferred chronic relapsing experimental autoimmune encephalomyelitis in the mouse. Neuropathologic analysis. Lab. Invest. 51:534-546.

30. Moore, G. R. W., U. Traugott, M. Farooq, and C. S. Raine. 1984. Experimental autoimmune encephalomyelitis: augmentation of demyelination by different myelin lipids. Lab. Invest. 51:416-424.

31. Deibler, G. E., R. E. Martenson, and M. W. Kies. 1972. Large scale preparation of myelin basic protein from central nervous system tissue of several mammalian species. Prep. Biochem. 2:139-165.

32. Trotter, J. L., and C. L. Wegeschiede. 1985. Isolation and purification of myelin proteolipid protein using high speed gel filtration in sodium dodecyl sulfate. Neurochem. Res. 10:865-869.

33. Tuohy, V. K., Z. Lu, R. A. Sobel, R. A. Laursen, and M. B. Lees. 1989. Identification of an encephalitogenic determinant of myelin proteolipid protein for SJL mice. J. Immunol. 142:1523-1527.

34. Bottomly, K., L. S. Davies, and P. E. Lipsky. 1991. Measurement of human and murine interleukin 2 and interleukin 4. In Current Procedures in Immunology. J. E. Colilgan, A. M. Kruisbeek, D. H. Margulies, E. M. Shevach, and W. Strober, editors. John Wiley \& Sons, Inc., New York. 6.3.1-6.3.12.

35. Ben-Nun, A., H. Wekerle, and I. R. Cohen. 1981. Vaccination against autoimmune encephalomyelitis with $\mathrm{T}$-lymphocyte line cells reactive against myelin basic protein. Nature (Lond.). 292:60-61.

36. Urban, J. L., V. Kumar, D. H. Kono, C. Gomez, S. J. Horvath, J. Clayton,
D. G. Ando, E. E. Sercarz, and L. Hood. 1988. Restricted use of T cell receptor $\mathrm{V}$ genes in murine autoimmune encephalomyelitis raises possibilities for antibody therapy. Cell. 54:577-592.

37. Acha-Orbea, H., D. J. Mitchell, L. Timmermann, D. C. Wraith, G. W. Tausch, M. K. Waldor, S. S. Zamvil, H. O. McDevitt, and L. Steinman. 1988 Limited heterogeneity of $\mathrm{T}$ cell receptors from lymphocytes mediating autoimmune encephalomyelitis allows specific immune intervention. Cell. 54:263-273.

38. Vandenbark, A., G. Hashim, and H. Offner. 1989. Immunization with a synthetic T-cell receptor V-region against experimental autoimmune encephalomyelitis. Nature (Lond.). 341:541-544.

39. Zaller, D. M., G. Osman, O. Kanagawa, and L. Hood. 1990. Prevention and treatment of murine experimental allergic encephalomyelitis with $\mathrm{T}$ cell receptor V $\beta$-specific antibodies. J. Exp. Med. 171:1943-1955.

40. Thompson, C. B., T. Lindsten, J. A. Ledbetter, S. L. Kunkel, H. A. Young, S. G. Emerson, J. M. Leiden, and C. H. June. 1989. CD28 activation pathway regulates the production of multiple T-cell-derived lymphokines/cytokines. Proc. Natl. Acad. Sci. USA. 86:1333-1337.

41. Trotter, J. L., K. G. Collins, and R. C. van der Veen. 1991. Serum cytokine levels in chronic progressive multiple sclerosis: interleukin-2 levels parallel tumor necrosis factor-alpha levels. J. Neuroimmunol. 33:29-36.

42. Panitch, H. S., R. L. Hirsch, J. Schindler, and K. P. Johnson. 1987. Treatment of multiple sclerosis with gamma interferon: exacerbations associated with activation of the immune system. Neurology. 37:1097-1102.

43. Selmaj, K., and C. S. Raine. 1988. Tumor necrosis factor mediates myelin and oligodendrocyte damage in vitro. Ann. Neurol. 23:339-346.

44. Hofman, F. M., D. R. Hinton, K. Johnson, and J. E. Merrill. 1989. Tumor necrosis factor identified in multiple sclerosis brain. J. Exp. Med. 170:607-612.

45. Ruddle, N. H., C. M. Bergman, K. M. McGrath, E. G. Lingenheld, M. L. Grunnet, S. J. Padula, and R. G. Clark. 1990. An antibody to lymphotoxin and tumor necrosis factor prevents transfer of experimental allergic encephalomyelitis. J. Exp. Med. 172:1193-1200.

46. Selmaj, K., B. Cannella, C. S. Raine, and C. F. Brosnan. 1991. Identification of lymphotoxin and tumor necrosis factor in multiple sclerosis lesions. $J$. Clin. Invest. 87:949-954.

47. Finck, B. K., P. S. Linsley, and D. Wofsy. 1994. Treatment of murine lupus with CTLA4Ig. Science (Wash. DC). 265:1225-1227.

48. Whitham, R. H., D. N. Bourdette, G. A. Hashim, R. M. Herndon, R. C. Ilg, A. A. Vandenbark, and H. Offner. 1991. Lymphocytes from SJL/J mice immunized with spinal cord respond selectively to a peptide of proteolipid protein and transfer relapsing demyelinating experimental autoimmune encephalomyelitis. J. Immunol. 146:101-107.

49. Sagerstrom, C. G., E. M. Kerr, J. P. Allison, and M. M. Davis. 1993 Activation and differentiation requirements of primary $\mathrm{T}$ cells in vitro. Proc. Natl. Acad. Sci. USA. 90:8987-8991.

50. Van de Velde, H., K. Lorre, M. Bakkus, K. Thielemans, J. L. Ceuppens, and $\mathrm{M}$. de Boer. 1993. CD45RO ${ }^{+}$memory $\mathrm{T}$ cells but not $\mathrm{CD}_{45 \mathrm{RA}^{+}}$naive $\mathrm{T}$ cells can be efficiently activated by remote co-stimulation with B7. Int. Immunol. 5:1483-1487.

51. McCarron, R. M., R. J. Fallis, and D. E. McFarlin. 1990. Alterations in $T$ cell antigen specificity and class II restriction during the course of chronic relapsing experimental allergic encephalomyelitis. J. Neuroimmunol. 29:73-79.

52. Perry, L. L., E. Barzaga-Gilbert, and J. L. Trotter. 1991. T cell sensitization to proteolipid protein in myelin basic protein-induced relapsing experimental allergic encephalomyelitis. J. Neurol. 33:7-15.

53. Lehmann, P. V., T. Forsthuber, A. Miller, and E. E. Sercarz. 1992. Spreading of T-cell autoimmunity to cryptic determinants of an autoantigen. Nature (Lond.). 35:155-157.

54. Cross, A. H., V. K. Tuohy, and C. S. Raine. 1993. Development of reactivity to new myelin antigens during chronic relapsing autoimmune demyelination. Cell. Immunol. 146:261-269. 